

\title{
Optimization of metallized film capacitor connection to reduce stray inductance
}

Theo Penven, Christian Martin, Charles Joubert, Marwan Ali, Régis Meuret, David Thomson, Maxime Semard

\section{- To cite this version:}

Theo Penven, Christian Martin, Charles Joubert, Marwan Ali, Régis Meuret, et al.. Optimization of metallized film capacitor connection to reduce stray inductance. IEEE Transactions on Components Packaging and Manufacturing Technology Part B, 2018, pp.1-1. 10.1109/TCPMT.2018.2874100 . hal-01946707

\section{HAL Id: hal-01946707 https://hal.science/hal-01946707}

Submitted on 6 Dec 2018

HAL is a multi-disciplinary open access archive for the deposit and dissemination of scientific research documents, whether they are published or not. The documents may come from teaching and research institutions in France or abroad, or from public or private research centers.
L'archive ouverte pluridisciplinaire HAL, est destinée au dépôt et à la diffusion de documents scientifiques de niveau recherche, publiés ou non, émanant des établissements d'enseignement et de recherche français ou étrangers, des laboratoires publics ou privés. 


\title{
Optimization of metallized film capacitor connection to reduce stray inductance
}

\author{
Théo Penven, Christian Martin Member, IEEE, Charles Joubert, Marwan Ali, Régis Meuret, David Thomson, \\ and Maxime Semard
}

\begin{abstract}
In power electronic applications, due to switching components, the inverter dc-bus generates current pulses at low and high frequencies. Usually, a dc-bus capacitor is sized to absorb the current peaks at the switching frequency, and to stabilize the DC voltage. For decoupling the high frequency (HF) harmonics, an additional capacitor is required. This decoupling capacitor needs to have a low impedance over a wide range of frequencies. However, their performances for the high frequency range are highly limited by their stray inductance. In order to minimize the need for an additional decoupling capacitor at high frequencies, this paper proposes to improve the connections of the DC bus capacitor. Busbar configuration and Printed Circuit Board (PCB) allow reducing parasitics of the cabling. Several types of interconnection are proposed and characterized in this study. Both 2-terminal and 4-terminal capacitors are evaluated and compared regarding operating frequency ranges. Measurement and modeling results show a significant improvement for HF decoupling by using quadrupole coaxial connections.
\end{abstract}

\section{Index Terms}

Capacitance measurement, Impedance measurement, Conductor layout, Metallized film capacitor, Resonance frequency, Stray Inductance. 


\section{Optimization of metallized film capacitor connection to reduce stray inductance}

\section{INTRODUCTION}

The design of power electronic converters trends toward higher density and higher performances. One way to increase power density is to increase switching frequency of the converter in order to minimize passive components (especially capacitor) and shrink the overall size of the converter. This trend requires passive components that operate at high frequency (up to few mega Hertz) [1].

Metallized film capacitors are wildly used in power electronic applications, because of their low dielectric loss factor, their high voltage operating range and their self-healing capabilities [2][3][4]. However, their performances and their bandwidth are reduced by their stray inductance, mostly due to the connections of the capacitor with electrical circuit devices [5][6][7]. As those capacitors are commonly used for decoupling function in power converters, it is necessary to take an interest in the layout of their connections in order to minimize their stray inductance $[8][9][6][10]$.

The purpose of this paper is to propose different types of layout to connect electrodes of metallized capacitors, and characterize them by using complex impedance measurements for different connections. The final objective is to find the best layout, leading to the lowest stray inductance as possible for the capacitor. Previous works have already focused on this topic [11] about different layouts for the connections with the windings of the capacitor (inner return conductor, central return conductor, external return conductor). However, there is still a lack of comparisons between those different types of layout for a same metallized film capacitor, in order to see the improvements brought by those connections on the behavior of the capacitor. Furthermore, besides using a classical twoterminal (dipole) connection of the capacitor, it is possible to connect it by using a four-terminal (quadrupole) circuit, in order to reduce even more the effects of stray inductance [12].

First, we will present the capacitor geometry and the experiment protocol chosen to carry out the characterizations to compare those different configurations. Then, we will compare the results for central and external returns of the current, and for different conductor materials. Finally, we will characterize a 4-terminal (quadrupole) connection and compare the results with those of 2-terminal(dipolar) layouts.

\section{EXPERIMENT PROTOCOL}

\section{A. Metallized film capacitors}

Metallized film capacitors are made of two polypropylene films, metallized on one of its sides to form the electrodes of the capacitor. The two films and the metallizations are wrapped around a hollow cylindrical mandrel, the whole forming the winding of the capacitor. The two ends of the winding are sprayed on both sides of the capacitor with thin metal particles, which allow the capacitor to be connected to the external circuit (figure 1) [13]. An electric field appears in the dielectric when a voltage is applied across the capacitor, and the current created by the variation of this electric field flows into the ends of the winding (sprayed end) and into the metallization, parallel to $\overrightarrow{e_{Z}}$ vector [11].

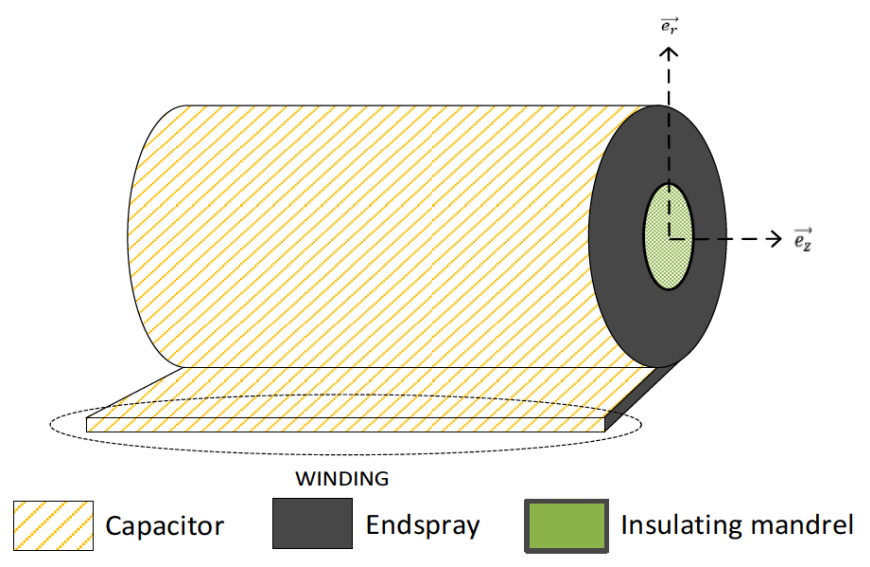

(a) General geometry of the capacitor
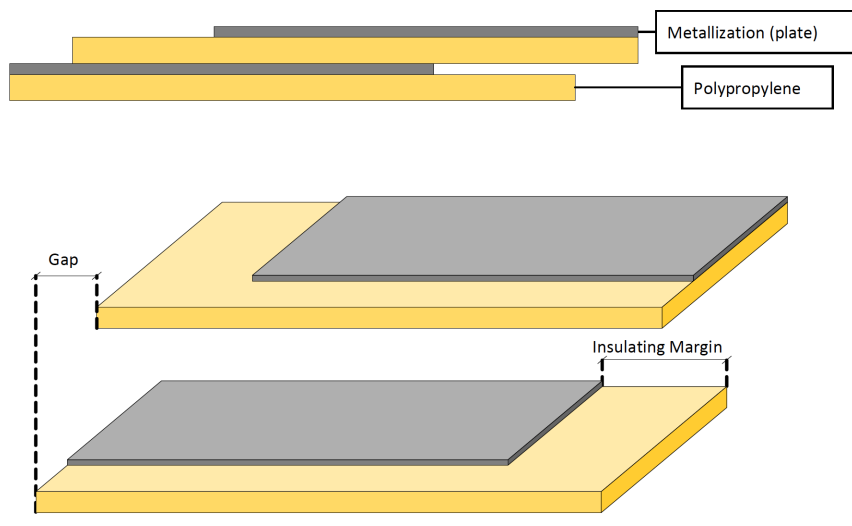

(b) The two polypropylene films with its metallization, forming the winding of the capacitor

Fig. 1: Description of polypropylene film capacitor

\section{B. Complex impedance measurement}

In order to measure the stray inductance ESL (Equivalent Series Inductance) of capacitors for different layouts of their return conductors, we carry out measurements of the complex impedance versus frequency. The measurement device used is an Agilent 4294A impedance analyzer [14] in the $1 \mathrm{kHz}$ 
to $40 \mathrm{MHz}$ frequency range and with an oscillator level of $500 \mathrm{mV}$. The electrical connection between the capacitor and the impedance analyzer is made with a double layer PCB, which allows to reduce the parasitic inductances and mutuals of the connections. Furthermore, a rigid printed circuit board (PCB) is used to ensure reproducible measurements. A large part of the remaining parasitic inductance of the test fixture can be eliminated with a proper open and short-circuit calibration. The residual inductance $L_{r}$ can be cancelled out by a differential measurement, involving two test benches.

The first test bench includes one capacitor. The total measured inductance $L_{m 1}$ is the sum of the real intrinsic inductance of the capacitor ESL, and the residual inductance $L_{r}$ of the test bench (equ 1).

$$
L_{m}=E S L+L_{r}
$$

The second test bench comprises two identical capacitors, connected in parallel. The total measured inductance $L_{m 2}$ is given by (equ 2)

$$
\left\{\begin{array}{l}
L_{m 1}=E S L+L_{r} \\
L_{m 2}=\frac{E S L}{2}+L_{r}
\end{array}\right.
$$

As we use the same PCB support for the two measurements, we can consider that the residual parasitic inductance $L_{r}$ of the test facility is the same in both cases. By measuring $L_{m 1}$ and $L_{m 2}$, we can deduce the ESL and the residual inductance of the test bench $L_{r}$ (equ 3).

$$
\left\{\begin{array}{l}
E S L=2\left(L_{m 1}-L_{m 2}\right) \\
L_{r}=2 L_{m 2}-L_{m 1}
\end{array}\right.
$$

In order to calculate the stray inductances $L_{m 1}$ and $L_{m 2}$ by using the complex impedance measurement, we use the value of the first serial resonance frequency which directly depends on the capacitance $C$ and the stray inductance (equ 4).

$$
f_{r}=\frac{1}{2 \pi \sqrt{L_{m} C}}
$$

Capacitance $C$ is calculated by using the value of the complex impedance before this first serial resonance frequency, at low frequency. The stray inductance of the test benches are given by (equ 5).

$$
\left\{\begin{array}{l}
L_{m 1}=\frac{1}{C\left(2 \pi f_{r 1}\right)^{2}} \\
L_{m 2}=\frac{1}{C\left(2 \pi f_{r 2}\right)^{2}}
\end{array}\right.
$$

The value of the complex impedance of the capacitor at the resonance frequency corresponds directly to its stray resistance, as the reactances of the capacitance and the stray inductance compensate each other at this specific frequency. Using this method, 3 layouts are charaecterized with different positions of conductors:

- Central return conductor (inside the mandrel)

- External return conductor

- Both central and external return conductors

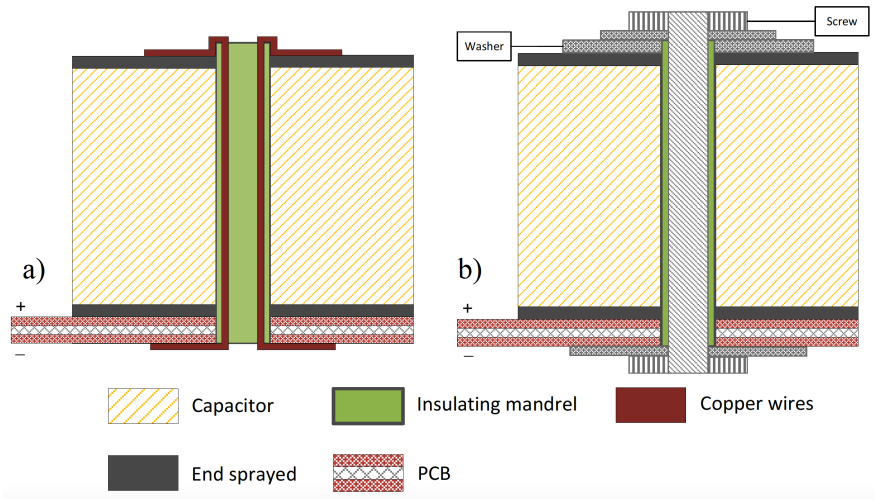

Fig. 2: Capacitor with central return conductors - a) Return by copper wires and b) Return by screw

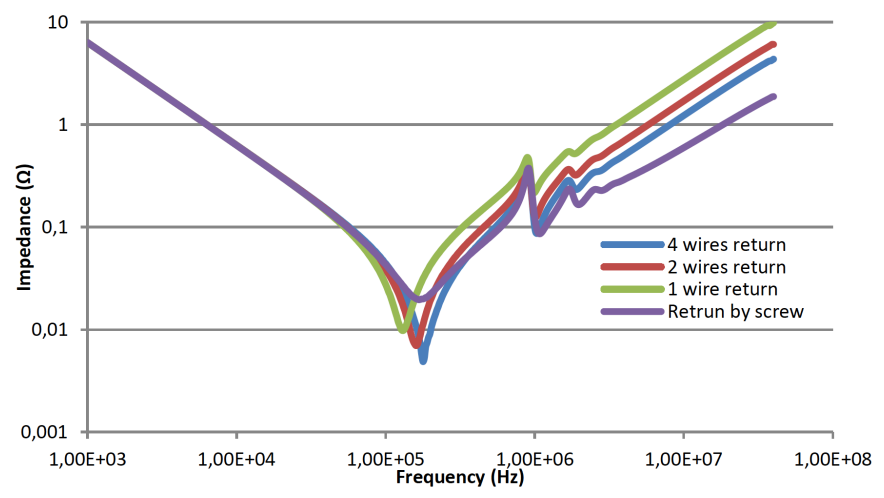

Fig. 3: Complex impedance vs frequency for different central return conductors

\section{Central Return CONDUCTOR}

As described in the presentation of capacitors, metalized polypropylene films are winded around a hollow cylindrical mandrel, allowing the passage of return currents inside the winding through the mandrel. This mandrel is made of an insulating material, avoiding the electrical contact between the return conductor and the winding.

For the first test, the return conductors are copper wires of $1 \mathrm{~mm}$ in diameter, soldered on the upper sprayed end and passing through the insulating mandrel to the inferior conductive layer of the PCB (figure 2a). In this layout, several configurations are tested with different number (one, two and four) of conductors in order to evaluate the influence of this number on the stray inductance of the capacitor.

We also evaluate a configuration where the return conductor is made of a unique steel screw (figure $2 b$ ). Both extremities of the screw are tightened with bolts to two washers, in contact respectively with the upper end sprayed of the capacitor and the bottom layer of the PCB.

The complex impedances for the various configurations are measured and are plotted on figure 3 . The differential method described in section II-B is used to determine the stray inductance, and the results are given in table I.

Concerning the central returns by wires, according to the results in table I, we can notice that both stray inductance and resistance values of the capacitor significantly decrease 
TABLE I: Results from the characterizations for different central return conductors

\begin{tabular}{|c|c|c|c|c|}
\hline Type & Capacitance $(\mu \mathrm{F})$ & Stray resistance $(\mathrm{m} \Omega)$ & Stray Inductance $(\mu \mathrm{H})$ & Resonance frequency $(\mathrm{kHz})$ \\
\hline 1 wire & 25.3 & 9.8 & 65.89 & 129.4 \\
\hline 2 wires & 25.2 & 6.9 & 45.28 & 160.1 \\
\hline 4 wires & 25.2 & 4.8 & 38.89 & 177.9 \\
\hline Screw & 25.2 & 19.5 & 21.7 & 166.9 \\
\hline
\end{tabular}

when the number of wire increases. As a consequence, the resonance frequency increases with the number of return wires. This is due to the fact that the different conductors are arranged in parallel. Yet, the global inductance is not inversely proportional to the number of conductors, likely because of the mutual inductance between wires.

In the case of the return by screw, the parasitic inductance is significantly lower than with copper wires. This is mainly due to the fact that the screw allows to increase the conductive surface of the return conductor, and presents a real axial symmetry [11]. Thus if we want to increase the performances of the capacitor by using current returns by wires, it would be necessary to increase the number of wires to get the same geometric characteristics as the screw.

Plus, we can observe that the stray resistance of the capacitor increases by using the screw. This is due to the fact that the wires are soldered to the plate of the capacitor, whereas the screw is only tightened with the capacitor, decreasing the electrical contact.

To conclude, it is more interesting to use a screw made of a reliable conductive material and soldered to its ends with the capacitor and the PCB. Ideally, using a screw of the same size as the insulating mandrel allows to optimize the conduction volumes. In addition, the advantage of using a screw is that it is tightened on washers in the upper plate, which tends to directly improve the contact between the lower plate of the capacitor and the upper layer of the PCB. It would be interesting to carry out a study to find the torque that can achieve the best results.

\section{EXTERNAL RETURN CONDUCTORS}

\section{A. Return conductors by copper wires}

In this section, we shall consider where the return conductors are located outside of the winding. We use the same copper wires as previously: they are soldered on the upper plate of the capacitor, passing along the winding to the bottom conductive layer of the PCB. As before, a variable number of return conductors is tested in order to observe the influence of this number on the behavior of the capacitor. We use consecutively one, two and four return conductors. To maximize the direct contact between the lower plate of the capacitor and the PCB, a screw is used, passing through the insulating mandrel and tightened at its extremities. To avoid unwanted currents, the screw is isolated from the plate of the capacitor and the layer of the PCB by using plastic washers at each end of the screw (Figure 4).

We follow the same protocol as before (figure 5) and compare the results for different numbers of copper wires (Table II).



Fig. 4: Capacitor with four external return wires

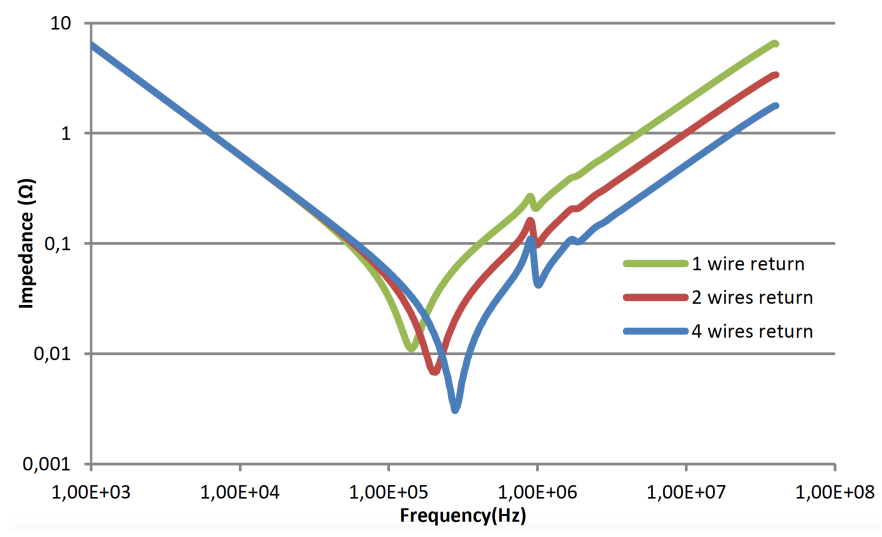

Fig. 5: Complex impedance vs frequency for different external return conductors

As in the case of internal return conductors, better results in terms of resistance and parasitic inductance are obtained for a large number of return conductors. The best results are also obtained for external conductors instead of central ones. Despite the fact that the serial stray resistance is slightly modified, we succeed to significantly reduce the parasitic inductance from $38.89 \mathrm{nH}$ to $11.93 \mathrm{nH}$ for four central and external return conductors respectively. Thus, the bandwidth of the capacitor increases significantly, as the resonance frequency is increased from $177.9 \mathrm{kHz}$ to $283.9 \mathrm{kHz}$ respectively.

We find the explanation for this trend in the expression of the magnetic field created by the return conductors [11]. According to Ampere's law, for the same current through the return conductors, the magnetic field created by the external returns will be lower than the one created by the internal returns, due to the increase of the path of this magnetic field in the case of the use of external return conductors. Thus, the inductance created by those magnetic fields will be lower in the case of external returns than in the case of central returns. 
TABLE II: Results for different number of external return conductors

\begin{tabular}{|c|c|c|c|c|}
\hline Type & Capacitance $(\mu \mathrm{F})$ & Stray resistance $(\mathrm{m} \Omega)$ & Stray Inductance $(\mu \mathrm{H})$ & Resonance frequency $(\mathrm{kHz})$ \\
\hline 1 wire & 25.3 & 10 & 46.03 & 140.8 \\
\hline 2 wires & 25.2 & 6.8 & 20.35 & 206.5 \\
\hline 4 wires & 25.2 & 3.9 & 11.93 & 283.9 \\
\hline
\end{tabular}

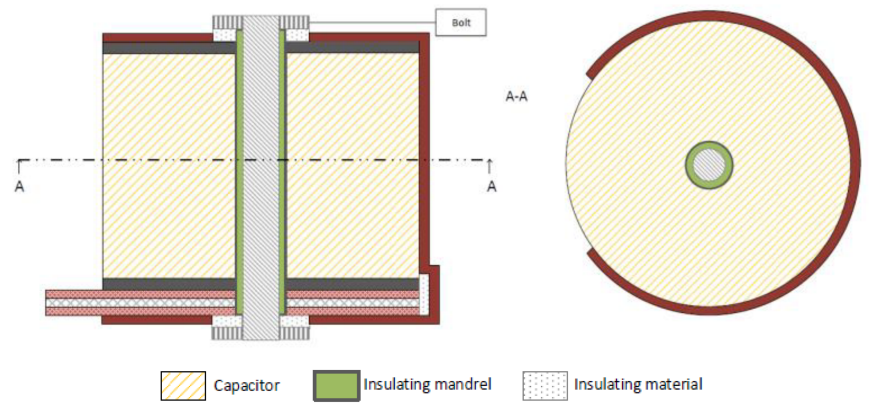

Fig. 6: Capacitor with external return by copper tape

\section{B. Return conductors by an adhesive copper tape}

It is possible in the case of external return conductors to achieve better results than before by opting for a different type of conductor. The objective is firstly to have the largest conductive surface possible in order to minimize the serial resistance. Then, inductive loops created by return conductors can be limited by putting those return conductors near the winding of the capacitor. To limit even more the parasitic inductance, it would be necessary to have a current conductor with an axial symmetry [11].

Bearing in mind these requirements, we use conductive adhesive strips of copper tape as return conductors. The width and the thickness of the copper tape are $5 \mathrm{~cm}$ and $66 \mu \mathrm{m}$ respectively. This copper strips are pasted on the upper plate of the capacitor and pass along the winding of the capacitor. Thus, as with previous experiments with wires, we evaluate different numbers of return strips. We also use a screw passing through the insulating mandrel (section IV-A) to optimize the contact between the lower plate of the capacitor and the PCB. We insulate the screw using plastic washers at each end of the screw (figure 6).

The impedance obtained for three numbers of strips is plotted on figure 7 and both inductances and resistances are given in table III.

As with the previous characterizations, the performances are improved when the number of copper strips increases. The stray inductance decreases significantly by using copper strips: indeed, the parasitic inductance is equal to $11.93 \mathrm{nH}$ with four external return wires, whereas a $4.12 \mathrm{nH}$ stray inductance is achieved with 3 copper strips. As a consequence, the resonance frequency is improved to $560.2 \mathrm{kHz}$ with 3 copper strips.

Closer analysis of figure 7 shows secondary resonances after the first serial resonance. These resonances are already visible in figures 3 and 5, but with lower amplitudes. They are specific of the capacitor winding and technology only. They are a direct result of the inhomogeneous distribution of current

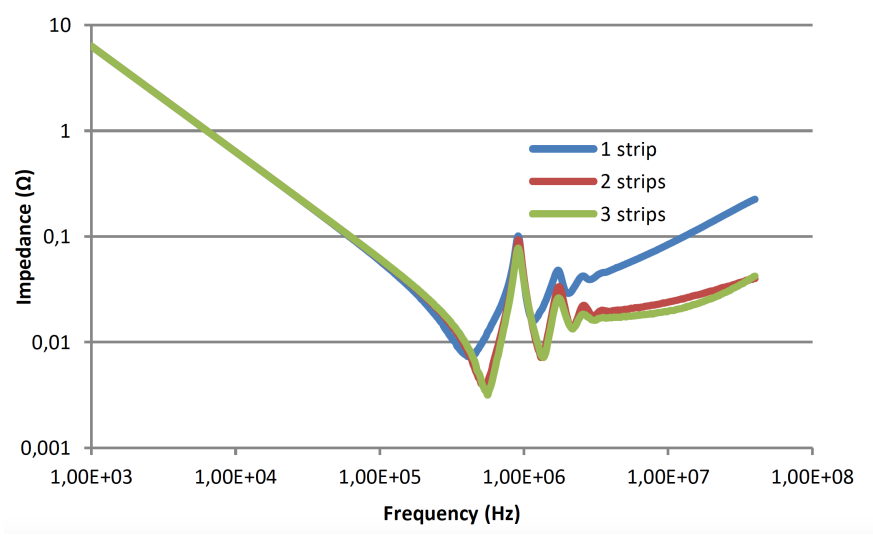

Fig. 7: Complex impedance vs frequency for different number of copper tape

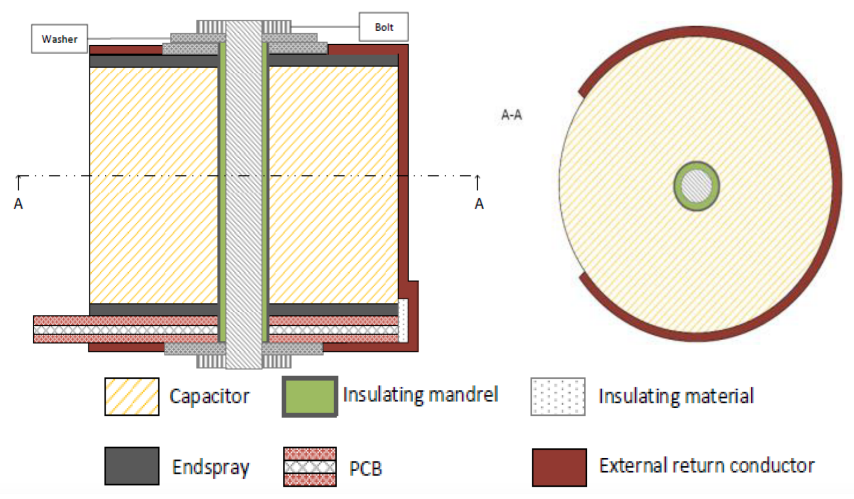

Fig. 8: Capacitor with both external and central returns

in the winding for high frequencies [15], which induces a significant variation of the impedance of the capacitor. The clear appearance of the secondary resonances in figure 7 is a consequence of the very low value of the stray inductance. In less careful layout, these resonances are masked by the higher value of ESL.

\section{INTERNAL AND EXTERNAL RETURN CONDUCTORS}

In this section, the performances of a capacitor combining internal and external return conductors are investigated (figure 8). Different numbers of return strips are experimented to observe the impact on performances, and the same screw as the one described in section III is used. Once again, the two extremities of the screw are tightened thanks to bolts against two washers to make the electrical contact.

The results are plotted on figure 9 and detailed in table IV.

As with the previous characterizations, we note that the performances are improved by increasing the number of 
TABLE III: Results for different number of external return conductors by copper strips

\begin{tabular}{|c|c|c|c|c|}
\hline Type & Capacitance $(\mu \mathrm{F})$ & Stray resistance $(\mathrm{m} \Omega)$ & Stray Inductance $(\mu \mathrm{H})$ & Resonance frequency $(\mathrm{kHz})$ \\
\hline 1 strip & 25.2 & 7.3 & 8.33 & 407.4 \\
\hline 2 strips & 25.2 & 3.8 & 5.01 & 525.6 \\
\hline 3 strips & 25.2 & 3.2 & 4.12 & 560.2 \\
\hline
\end{tabular}

TABLE IV: Results for different number of external return conductors by copper strips and one screw

\begin{tabular}{|c|c|c|c|c|}
\hline Type & Capacitance $(\mu \mathrm{F})$ & Stray resistance $(\mathrm{m} \Omega)$ & Stray Inductance $(\mu \mathrm{H})$ & Resonance frequency $(\mathrm{kHz})$ \\
\hline 1 strip & 25.2 & 6.5 & 4.9 & 453.1 \\
\hline 2 strips & 25.2 & 3.4 & 2.59 & 622.9 \\
\hline 3 strips & 25.2 & 2.7 & 2.59 & 663.9 \\
\hline
\end{tabular}

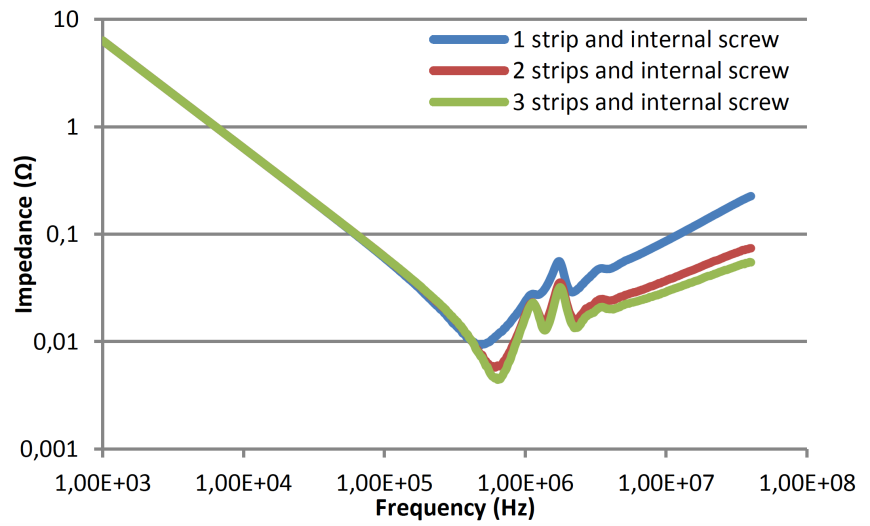

Fig. 9: Complex impedance vs frequency for different number of copper tape and one screw

copper strips. We also observe that the performances are better than those obtained for either internal (section III) or external (section IV) conductors. Indeed, the stray inductance decreases significantly from $4.12 \mathrm{nH}$ with 3 copper strips to $2.59 \mathrm{nH}$ by using the 3 copper strips configuration and the screw. Likewise, the bandwidth of the capacitor significantly increases, as the first serial resonance occurs for a frequency of $663.9 \mathrm{kHz}$. We can also observe that in this configuration the amplitude of the first secondary resonance significantly decreases compared with those obtained previously.

\section{4-TERMINAL CONNECTION}

As stated before, the bandwidth of metalized capacitors is reduced by their stray inductance. This parasitic inductance is mostly due to the connections of the capacitor with the electrical circuit devices, and also to the magnetic field created by the currents in the winding. In order to cancel those parasitics, and therefore limit the inductive behavior of the capacitor at the high frequency range, a 4-terminal connection is evaluated, with two main objectives:

- To minimize the stray inductance due to the connections of the capacitor with the electrical circuits.

- To minimize the stray inductance due to magnetic coupling in the winding, by choosing a specific layout of the connections with the winding.

The 4-terminal connection scheme is shown in figure $10 \mathrm{~b}$. This scheme allows to separate the disturbing circuit and the victim circuit (figure 10a). With this layout, at high frequency, disturbing circuit and victim circuit are completely separated magnetically: the connection of the first one is passing inside the winding whereas connections of the second one are made at the outside of the capacitor. In this case, the high frequency currents in the disturbing circuit concentrate at the center of the capacitor, whereas those of the victim circuit flow along the external part of the winding. This separation prevents the spread of the magnetic field from the disturbing circuit to the victim circuit, which allows to significantly attenuate the high-frequency disturbances between the two circuits. Also, if we select conductors (internal screws and adhesive tape on the periphery) with a perfect axial symmetry, the mutual inductance between the two circuits can be totally canceled [12].

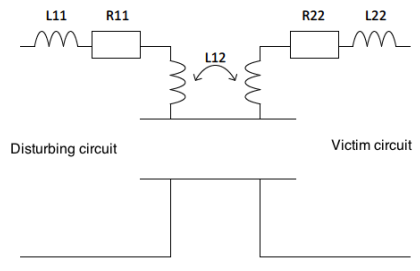

(a) Equivalent circuit model

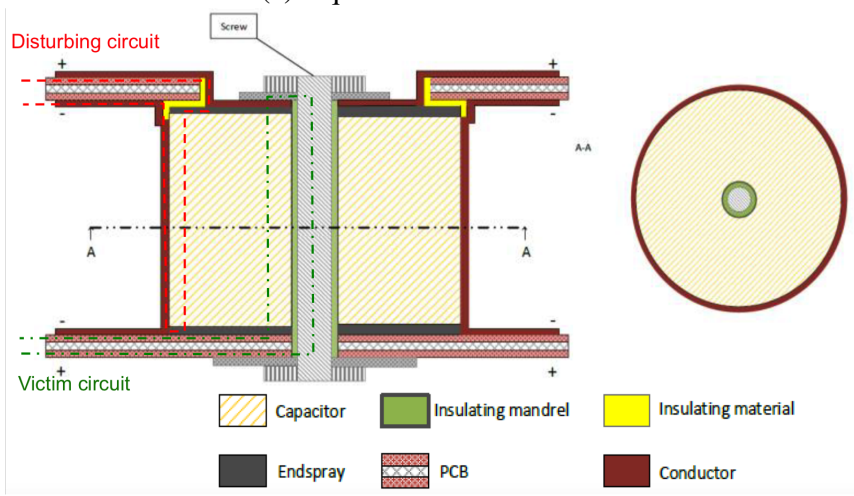

(b) Connections

Fig. 10: capacitor with 4-terminal configuration

In order to characterize this connection scheme, we measure the S-parameters of the capacitor with a Vector Network Analyzer (VNA) [16] [17], and deduce the impedance parameters (Z-parameters) [18]. The measurements are performed in the $20 \mathrm{kHz}$ to $100 \mathrm{MHz}$ frequency range. 


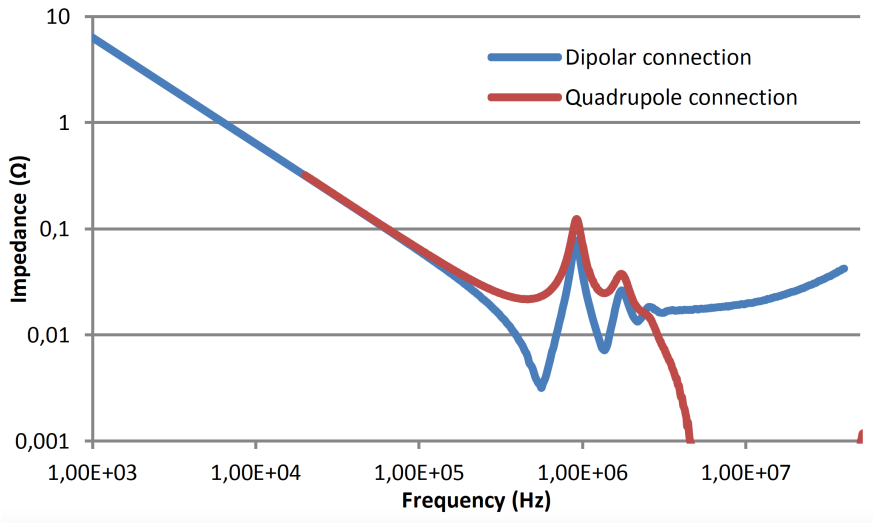

Fig. 11: Complex impedance vs frequency for a 2-terminal and a 4-terminal connections

Similarly to the measurements with the impedance analyzer, the coaxial connections between the VNA and the device under test are compensated by performing open circuit, shortcircuit, load and phase calibrations. The results for 2-terminal and 4-terminal connections are given on figure 11. The results obtained for the 2-terminal connection (blue curve) are those obtained in the complex impedance measurements for an external return conductor with 3 copper strips. The results given for the 4-terminal connection (red curve) come from the S-parameters measurements of the device depicted on figure 10 .

The 4-terminal connection presents similar characteristics in terms of complex impedance compared to the 2-terminal connection for the low frequency range: the capacitive part of the curve remains unchanged. The interest of our 4-terminal scheme resides in the value of its impedance for high frequencies (figure 11). Indeed, after the first serial resonance frequency, the complex impedance of the capacitor exhibits an inductive behavior, but only for a limited frequency range. For higher frequencies, an abrupt fall of the complex impedance of the capacitor is observed, and its impedance tends towards zero. In this case, disturbing circuit and victim circuit are completely separated, as the fall of this impedance for high frequencies prevents the propagation of disturbances between the two circuits, which presents a considerable interest for a high frequency decoupling application.

\section{FREQUENCY MODELLING}

This behavior is confirmed by an analytical model developed in [12][15] which describes the behavior of metalized film capacitor. This model computes the impedance of the capacitor by taking into account the impedance of the metalized foil (based on current repartition), the impedance of the terminations and the parasitic inductance due to the return conductor. This model is based on the telegrapher's equations applied on capacitor with cylindric foils (equ. 6) [15][19][20].

$$
\left\{\begin{array}{l}
\frac{\partial V(r)}{\partial r}=-L(r) \omega j I(r) \\
\frac{\partial I(r)}{\partial r}=-Y(r) V(r)
\end{array}\right.
$$

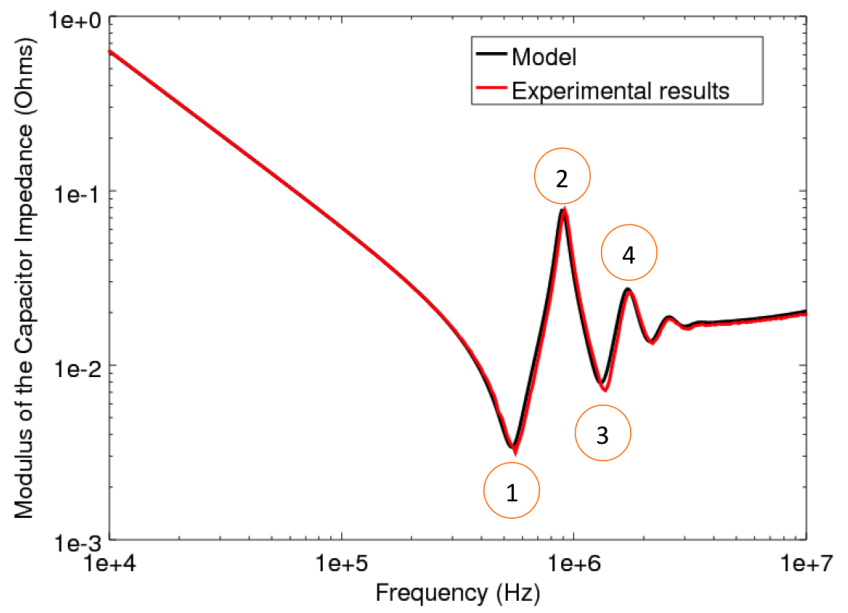

Fig. 12: Model and measurement comparison of capacitor impedance modulus

It can be noted that, because of the cylindrical structure of the capacitor, the inductance $L$ and the admittance $Y$ depend on the distance to the centre $r$. The solution of these equations are detailled in [15] and presented in equ 7 where $\gamma=\sqrt{-j \omega L(r) Y(r)}=\sqrt{-j \omega \mu_{0} Y(r)}$ and $J_{n}, Y_{n}$ are respectively the Bessel functions of first and second kind. $A_{1}$ and $A_{2}$ are constants which depends upon the connection scheme (central or external return conductor).

$$
\left\{\begin{array}{l}
V(r)=A_{1} \cdot J_{0}(\gamma r)+A_{2} \cdot Y_{0}(\gamma r) \\
I(r)=\frac{2 \pi \gamma}{j \omega \mu_{0} h r}\left(A_{1} \cdot J_{1}(\gamma r)+A_{2} \cdot Y_{1}(\gamma r)\right)
\end{array}\right.
$$

Z-parameters are given by equ 8 :

$$
\left\{\begin{array}{l}
Z_{11}=V\left(R_{\text {out }}\right) / I\left(R_{\text {out }}\right) \\
Z_{21}=V\left(R_{\text {in }}\right) / I\left(R_{\text {out }}\right) \\
Z_{12}=V\left(R_{\text {out }}\right) / I\left(R_{\text {in }}\right) \\
Z_{22}=V\left(R_{\text {in }}\right) / I\left(R_{\text {in }}\right)
\end{array}\right.
$$

where $R_{\text {in }}$ and $R_{\text {out }}$ are respectively the inner and outer radius of the capacitor.

Main parameters of the model include the diameter of the capacitor, the height and the capacitance. These parameters are obtained from manufacturer data. Besides, the resistance of the metallization has a great impact on the secondary resonance magnitude. This parameter is not given in datasheets and is deduced by plot fitting to the measured impedance detailed in section IV-B. In figure 12, we can observe the capacitive behavior of the capacitor up to $500 \mathrm{kHz}$ and then the serial and parallel resonances. Table $\mathrm{V}$ describes serial and parallel resonance values.

TABLE V: Serial and parallel resonance values

\begin{tabular}{|c|c|c|c|c|}
\hline & 1 & 2 & 3 & 4 \\
\hline Frequency $(\mathrm{kHz})$ & 538 & 893 & 1290 & 1690 \\
\hline Impedance $(\mathrm{m} \Omega)$ & 4 & 88.5 & 7.86 & 31.1 \\
\hline
\end{tabular}




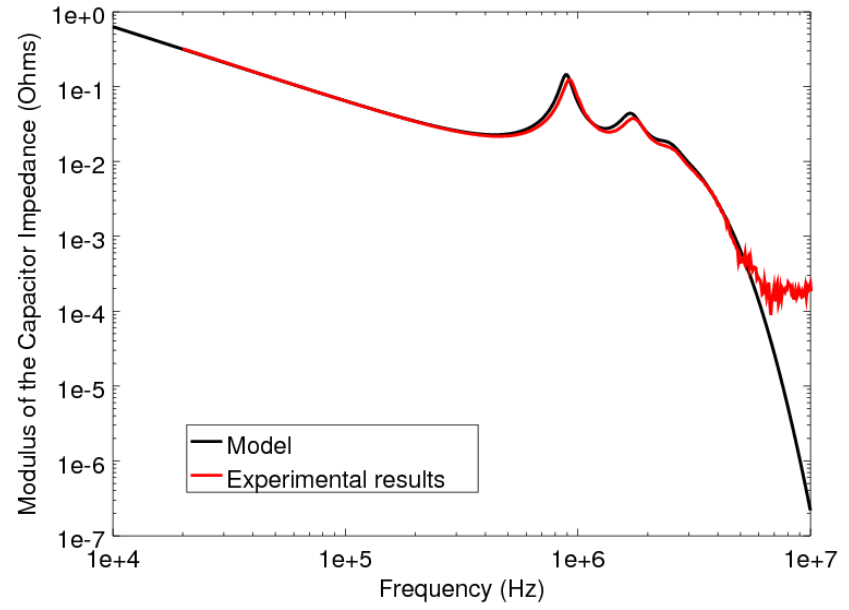

Fig. 13: Model and measurement comparison of capacitor impedance modulus in quadrupole configuration

In figure 11, we notice that the quadrupole configuration allows to cancel out the effets due to stray inductances. Based on the quadrupole capacitor model detailled in [12] and with the same parameters used previously, the frequency behavior of the impedance of the capacitor is computed. Modeling and measurements results are shown in figure 13. Modeling results and measurements are in good agreement in the $10 \mathrm{kHz}$ to $6 \mathrm{MHz}$ frequency range. The model describes the decrease of the impedance in high frequency.The impedance drop after $500 \mathrm{kHz}$, corresponding to resonance frequency in 2-terminal configuration, clearly appears. Above $6 \mathrm{MHz}$, the measured impedance remains constant wheras impedance computed from the model still decreases. This is an artifact resulting from the noise floor of the VNA.

\section{CONCLUSION}

The objective of this paper was to propose different connection schemes of metalized film capacitors used for decoupling function, in order to increase their bandwidth. For decoupling, parasitic inductances - due to connections and internal magnetic field - must be kept as low as possible. We characterized firstly several 2-terminal connections, for different layouts of return conductors.

Thus, in general, we can retain the following strategies to optimize the performances of our capacitor:

- favor external return conductors, or both external and central return conductors if the capacitor geometry allows it.

- in all cases, put return conductors as close as possible to the capacitor winding, either if the conductors are inside or outside the winding.

- try as much as possible to increase the section of the conductors.

- place conductors symmetrically to the axis of the capacitor.

We also characterized a 4-terminal connection, with a specific layout of the current conductors, in order to cancel the propagation of the high frequency disturbances. In this layout, both disturbing and victim circuits are magnetically separated by the winding of the capacitor itself: the highfrequency currents in the disturbing circuit concentrate at the center of the capacitor, whereas those of the victim circuit concentrate near the external surface of the winding. This allows to prevent the spread of the magnetic field in the victim circuit, and so to reduce the propagation of the high-frequency disturbances.

\section{ACKNOWLEDGMENT}

The authors would like to thank Safran and Industrial Capacitors (Wrexham) Limited for their financial support and for supply components respectively.

\section{REFERENCES}

[1] J. W. Kolar, F. Krismer, and H.-P. Nee, "What are the big challenges in power electronics?" In Proceedings of CIPS, Nüremberg, 2014 (cit. on p. 1).

[2] A. Kartal, "Review of film capacitor trends and design changes as a result of improved technologies in power electronics," in PCIM Europe 2017; International Exhibition and Conference for Power Electronics, Intelligent Motion, Renewable Energy and Energy Management, May 2017, pp. 1-3 (cit. on p. 1).

[3] R. H. T. Wilke, A. Baker, H. Brown-Shaklee, R. Johnson-Wilke, C. Hettler, T. Murata, P. O'Malley, S. Perini, and M. Lanagan, "Fabrication of wound capacitors using flexible alkali-free glass," IEEE Transactions on Components, Packaging and Manufacturing Technology, vol. 6, no. 10, pp. 1555-1560, Oct. 2016, ISSN: 2156-3950. DOI: 10.1109/TCPMT.2016.2600946 (cit. on p. 1).

[4] R. Robutel, C. Martin, C. Buttay, H. Morel, P. Mattavelli, D. Boroyevich, and R. Meuret, "Design and implementation of integrated common mode capacitors for sic-jfet inverters," IEEE Transactions on Power Electronics, vol. 29, no. 7, pp. 3625-3636, Jul. 2014, ISSN: 0885-8993. DOI: 10.1109/TPEL.2013.2279772 (cit. on p. 1).

[5] T. Talbert, C. Joubert, N. Daude, and C. Glaize, "High frequency model of stacked film capacitors," Eur. Phys. J. Appl. Phys, vol. 16, no. 02, pp. 105-112, 2001 (cit. on p. 1).

[6] B. J. Pierquet, T. C. Neugebauer, and D. J. Perreault, "A fabrication method for integrated filter elements with inductance cancellation," IEEE Transactions on Power Electronics, vol. 24, no. 3, pp. 838-848, Mar. 2009, ISSN: 0885-8993. DOI: 10.1109/TPEL.2008.2011638 (cit. on p. 1).

[7] T. D. Oliveira, J. Schanen, J. Guichon, and J. Roudet, "Optimized layout for an emc filter: Analysis and validations," in International Symposium on Electromagnetic Compatibility - EMC EUROPE, Sep. 2012, pp. 1-6. DOI: 10.1109/EMCEurope . 2012 .6396768 (cit. on p. 1). 
[8] T. M. Zeeff, T. H. Hubing, T. P. V. Doren, and D. Pommerenke, "Analysis of simple two-capacitor lowpass filters," IEEE Transactions on Electromagnetic Compatibility, vol. 45, no. 4, pp. 595-601, Nov. 2003, ISSN: 0018-9375. DOI: 10.1109/TEMC.2003.819059 (cit. on p. 1).

[9] M. A. Brubaker, H. C. Kirbie, and T. A. Hosking, "Integrated dc link capacitor/bus structures to minimize external esl contribution to voltage overshoot," in 2012 IEEE Transportation Electrification Conference and Expo (ITEC), Jun. 2012, pp. 1-6. DOI: 10.1109/ITEC. 2012.6243453 (cit. on p. 1).

[10] P. Gonzalez-Vizuete, F. Fico, A. Fernandez-Prieto, M. J. Freire, and J. B. Mendez, "Calculation of parasitic self and mutual inductances of thin film capacitors for power line filters," IEEE Transactions on Power Electronics, pp. 1-1, 2018, ISSN: 0885-8993. DOI: 10.1109/TPEL. 2018.2824658 (cit. on p. 1).

[11] S. Siami, N. Daude, C. Joubert, and P. Merle, "Minimization of the stray inductance in metallized capacitors: Connections and winding geometry dependence," EPJ Appl. Phys., vol. 4, pp. 37-44, 1998 (cit. on pp. 1, $3,4)$.

[12] C. Joubert, "Etude des phénomènes électromagnétiques dans les condensateurs à films métallisés-nouvelle génération de condensateurs," $\mathrm{PhD}$ thesis, Ecole Centrale de Lyon, 1996 (cit. on pp. 1, 5-7).

[13] EPCOS, "Film capacitors : General technical information," TDK, Tech. Rep., Sep. 2015. [Online]. Available: https : / / en . tdk . eu / download / 530754 / bb7f3c742f09af6f8ef473fd34f6000e / pdf generaltechnicalinformation.pdf (cit. on p. 1).

[14] Agilent, Accurate impedance measurement with cascade microtech probe system, Application Note 1369-3 (cit. on p. 1).

[15] S. Siami, C. Joubert, and C. Glaize, "High frequency model for power electronics capacitors," IEEE Transactions on Power Electronics, vol. 16, no. 2, pp. 157-166, Mar. 2001, ISSN: 0885-8993. DOI: 10.1109/63.911139 (cit. on pp. 4, 6).

[16] Leasametric, Vector network analyzer family zvr - 4 models for all requirements: Zvre, zvce, zvr, zvc, Leasametric (cit. on p. 5).

[17] S. Wang, F. C. Lee, and W. G. Odendaal, "Characterization and parasitic extraction of emi filters using scattering parameters," IEEE Transactions on Power Electronics, vol. 20, no. 2, pp. 502-510, Mar. 2005, ISSN: 0885-8993. DOI: 10.1109/TPEL. 2004.842949 (cit. on p. 5).

[18] H. Packard, S-parameter techniques for faster, more accurate network design, ed. by A. Note, 95-1, pp. 1-79 (cit. on p. 5).

[19] C. R. Sullivan and A. M. Kern, "Capacitors with fast current switching require distributed models," in 2001 IEEE 32nd Annual Power Electronics Specialists Conference (IEEE Cat. No.01CH37230), vol. 3, 2001, 1497-1503 vol. 3. DOI: 10.1109/PESC.2001.954331 (cit. on p. 6).
[20] C. R. Sullivan and Y. Sun, "Physically-based distributed models for multi-layer ceramic capacitors," in Electrical Performance of Electrical Packaging (IEEE Cat. No. 03TH8710), Oct. 2003, pp. 185-188. DOI: 10.1109/ EPEP.2003.1250028 (cit. on p. 6). 